\title{
Assessing hydration disturbances from concrete aggregates with radiation shielding properties by isothermal calorimetry
}

\author{
Lars Wadsö, ${ }^{1, *}$ Carsten P. Cooper-Jensen, ${ }^{2,3}$ and Phillip M. Bentley ${ }^{2,3}$ \\ ${ }^{1}$ Building Materials, Lund University, Box 118, 22100 Lund, Sweden \\ ${ }^{2}$ European Spallation Source ERIC, SE-221 00 Lund, Sweden \\ ${ }^{3}$ Department of Physics and Astronomy, Uppsala University, 75105 Uppsala, Sweden
}

(Received 10 October 2016; published 24 April 2017)

\begin{abstract}
Spallation sources create a large amount of neutrons with energies up to the $\mathrm{GeV}$ range. To shield for these neutrons, steel and concrete are important materials. By adding different aggregates to normal concrete, one can improve the shielding effect of the concrete. Some of these aggregates can influence the rate of hydration (reaction) of the cement or even completely inhibit the hydration. It is thus good practice to start the investigation of new shielding concretes by assessing the rate of cement hydration in the presence of new aggregates. This is preferably made with isothermal (heat conduction) calorimetry. In this paper we describe such tests made with a large number of different potential aggregates for a shielding concrete. We found a full range of influence on the hydration, from no influence to severely disturbed. In some cases smaller particles gave more disturbance.
\end{abstract}

DOI: 10.1103/PhysRevAccelBeams.20.043502

\section{INTRODUCTION}

The main ingredients of concrete are cement, water, sand and rocks. The aggregate part (sand and rocks) can in most cases be considered to be inert, but it is sometimes of interest to add unusual and possibly noninert aggregates to the concrete. Some cases where this occurs is when hazardous materials like heavy metals [1] or radioactive waste [2] are cast into concrete for long-term storage, or when concrete for radiation shielding needs to incorporate certain materials or elements [3]. It is then of interest to have protocols for testing how the added materials influence the hydration reaction and the formed product. We believe that it is most relevant to start such testing by an overall assessment of the kinetics of hydration, something that is most conveniently made by isothermal calorimetry.

Concrete is held together by the hardened cement paste that is formed during the hydration of the cement. This hydration (reaction) is a complex multistep process involving several different reactants and products [4]. One common way to visualize such a reaction is by the heat that it produces, i.e., by calorimetry. There are several different calorimetric techniques in use in cement science and technology [5], but the most useful for testing for hydration disturbances is isothermal (heat conduction) calorimetry. ASTM 1679 [6] gives a good overview of how isothermal

\footnotetext{
*lars.wadso@byggtek.1th.se

Published by the American Physical Society under the terms of the Creative Commons Attribution 4.0 International license. Further distribution of this work must maintain attribution to the author(s) and the published article's title, journal citation, and DOI.
}

calorimetry can be used in applied cement technology to investigate problems with hydration disturbances.

A calorimetric hydration curve can be changed by chemical additions in several ways. For example, the start of the main reaction can be accelerated or retarded, or the rate of the main reaction can be lowered. More serious changes in the rate of reaction can also occur, for example a complete inhibition of the hydration. If there is only retardation of the main reaction the hydration will usually proceed as normal, but take longer time, and this is then mainly a problem of turnaround and efficiency at the worksite. Other types of delayed hydration can be more serious as they indicate that the hydration reaction is not proceeding as it should; the final strength and other properties may then not develop as intended. Figure 1 schematically shows how cement hydration curves can change in different ways.

There have been several studies over the years on how various compounds influence the hydration of ordinary Portland cement (OPC) and its phases. For example Weeks et al. [7] investigated the influence of zinc and lead; they also gave data on how different inorganic salts influence the hydration of OPC. Bhatty [8] made a thorough review of how the elements influence both cement manufacturing and hydration.

As mentioned above, one situation where relatively large amounts of unusual materials should be added to concrete is when radiation shields are cast. The most common concrete shields are probably those cast with magnetite (iron ore) to protect against $\mathrm{X}$ and $\gamma$ radiation. Such shields are found for example at oncological radiation facilities at hospitals and at nuclear power plants. The mixing, transport and casting of magnetite concrete is challenging as it is 


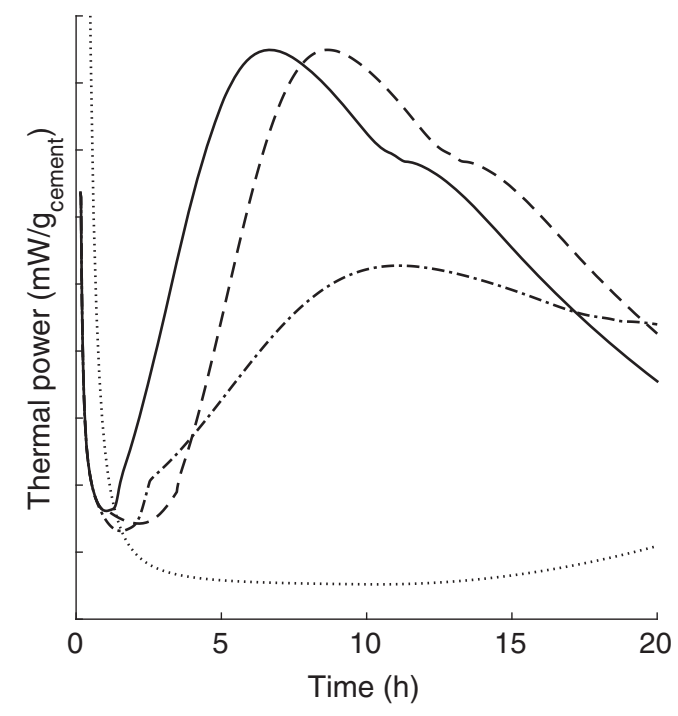

FIG. 1. Schematic illustration of how a calorimetric measurement of the hydration of a neat cement (solid line) can be changed by additions causing retardation (dashed line), lowered rate of the main reaction (dash-dotted line), or serious hydration disturbances (dotted line).

much heavier than ordinary concrete. Apart from this, magnetite can be used as an ordinary aggregate that does not influence the cement hydration.

The ongoing construction of the European Spallation Source (ESS), Lund, Sweden [9] has increased the interest for the shielding effect of concrete and how to possibly improve it. ESS will be creating neutrons with energies up to $2 \mathrm{GeV}$ by a spallation process where protons are accelerating into a tungsten target. Neutrons will be slowed down in a moderator to energies between $1 \mathrm{meV}$ to $1 \mathrm{eV}$ before they are led through beam guides, up to $150 \mathrm{~m}$ long, to the instruments where the neutrons are being used for different experiments. The target and the moderator are shielded by a $3.5 \mathrm{~m}$ thick layer of steel, to moderate most of the neutrons with energy above $10 \mathrm{MeV}$, but additional shielding of the moderator, the neutron guides and the instruments are needed. Concrete will be an important part of this shielding. It is important to remember that all metals have resonances in cross section (energies where there is increased interaction or very little interaction with neutrons) in the energy range between $1 \mathrm{keV}$ to $1 \mathrm{MeV}$.

The focus of this study can be divided into three types of concrete aggregates and their combinations.

Nonferrous metal based aggregates. - These will moderate high energy neutrons and at the same time have different cross section resonances than that of the iron shielding around the moderator in the $1 \mathrm{keV}$ to $1 \mathrm{MeV}$ region.

Hydrogen based aggregates.-Below $1 \mathrm{MeV}$ hydrogen has a high scattering cross section and for each interaction with a hydrogen atom the neutron is slowed down more than with an interaction with a metal atom. Between 1 and $10 \mathrm{MeV}$ the hydrogen cross section goes down but because of the large energy transfer in each interaction, hydrogen is still very efficient.

Large absorption cross-section aggregates.-Both cadmium and gadolinium have high cross section for absorbing slow neutrons, but are expensive, toxic and emit a lot of gamma radiation in the process, which then has to be attenuated. Lithium absorbs neutrons without emitting any photons but for approximately every 5000 absorbed slow neutrons lithium produces a neutron with energy above $1 \mathrm{MeV}$. Boron has a high absorption cross section for slow neutrons, and for each absorbed neutron a photon with $0.478 \mathrm{MeV}$ is emitted.

Although there are a large number of studies on the attenuating properties of different materials, there is comparatively little done on cement based materials, even if such materials are commonly used in radiation shields. Of the existing papers - theoretical, experimental or both-dealing with shielding properties of concrete, some deal with ordinary concrete [10], some deal with concretes with iron [11-15], and some with more innovative materials. Among the latter are studies of concrete with barite [13,16,17], boron-containing compounds [18-20], lead [21,22], magnetite and lead [23], and polymers [14,15]. ASTM C637 [24] also contains a list of different aggregates used in radiation shielding concrete.

Most of the above papers do not mention the hydration kinetics of the concrete. A few studies $[18,19]$ mention the retarding properties of boron containing minerals, used to shield slow neutrons. This effect of compounds with boron is also known from other studies. For example, Kratochvíl et al. [25] have studied how additions of different boron compounds (up to $2 \%$ of the cement mass) affected the setting of Portland cement. The reason for performing the study was that gypsum from boric acid manufacturing may be used instead of natural gypsum in the production of cement, but it contains boron compounds that may delay the hydration of the cement [26]. Kratochvil et al. found that boron (the element) had no effect on the hydration, but boric acid and borax gave a significant retardation. It has also been shown that boron containing waste from borax manufacturing retards hydration [20].

As discussed above, materials added to concrete for different purposes may disturb the normal hydration kinetics of the cement paste, and it is therefore natural to investigate this as a first step in designing radiation shields with unusual materials. We will in this paper describe how isothermal calorimetry was used in such a study.

\section{MATERIALS AND METHODS}

\section{A. Materials}

We have tested eight materials and one combination of materials that potentially have a use as aggregates in concrete shielding as they contain boron, hydrogen, tungsten or copper. The materials are described in Table I. The percentages of materials added approximately represent the 
TABLE I. The tested aggregates. The chemical formulas are for the chemically pure compounds.

\begin{tabular}{|c|c|c|c|}
\hline A & Polyethylene (PE) & {$\left[\mathrm{C}_{2} \mathrm{H}_{4}\right]_{n}$} & Particle diameter $2.5,5$ and $10 \mathrm{~mm}$ \\
\hline B & Borax & $\mathrm{Na}_{2}\left[\mathrm{~B}_{4} \mathrm{O}_{5}(\mathrm{OH})_{4}\right] \cdot 8 \mathrm{H}_{2} \mathrm{O}$ & Pure fine powder \\
\hline $\mathrm{C}$ & $\begin{array}{l}\text { Polypropylene (PP) } \\
\text { with borax }\end{array}$ & {$\left[\mathrm{C}_{3} \mathrm{H}_{6}\right]_{n}$ and $\mathrm{Na}_{2}\left[\mathrm{~B}_{4} \mathrm{O}_{5}(\mathrm{OH})_{4}\right] \cdot 8 \mathrm{H}_{2} \mathrm{O}$} & $\begin{array}{l}\text { Particle diameter } 4 \mathrm{~mm} .20 \% \text { borax was mixed } \\
\text { into the melted PP before extrusion of particles }\end{array}$ \\
\hline $\mathrm{D}$ & Malachite & $\mathrm{Cu}_{2} \mathrm{CO}_{3}(\mathrm{OH})_{2}$ & $\begin{array}{l}\text { Mining product; particle diameters }<1.5 \mathrm{~mm}(\mathrm{~S}) \\
\text { and }<6 \mathrm{~mm}(\mathrm{M})\end{array}$ \\
\hline $\mathrm{E}$ & Bornite & $\mathrm{Cu}_{5} \mathrm{FeS}_{4}$ & $\begin{array}{l}\text { Mining product; particle diameters }<1.5 \mathrm{~mm}(\mathrm{~S}) \\
\text { and }<6 \mathrm{~mm}(\mathrm{M})\end{array}$ \\
\hline $\mathrm{F}$ & Colemanite powder (pure) & $\mathrm{CaB}_{3} \mathrm{O}_{4}(\mathrm{OH})_{3} \cdot \mathrm{H}_{2} \mathrm{O}$ & Pure fine powder \\
\hline G & Colemanite raw & $\mathrm{CaB}_{3} \mathrm{O}_{4}(\mathrm{OH})_{3} \cdot \mathrm{H}_{2} \mathrm{O}$ & Mining product; particle diameter $<1.5 \mathrm{~mm}$ \\
\hline $\mathrm{H}$ & Tungsten oxide & $\mathrm{WO}_{3}$ & Industrially produced; fine particles \\
\hline I & Boron carbide & $\mathrm{B}_{4} \mathrm{C}$ & Industrially produced; particle diameter $0.5-1 \mathrm{~mm}$ \\
\hline
\end{tabular}

range from no addition to a very high addition, related to their shielding capacity. All materials were of commercial origin except the polypropylene (PP) blended material that was made specifically for this study. As the aim of this study was to describe a systematic and efficient method to assess hydration disturbances, we do in most cases not discuss the reason for the behavior we see; many of the samples are commercial products that lack information on their exact composition. The results shown should thus not be taken to represent all similar materials as minor constituents in aggregates may completely change the hydration kinetics.

The used cement was a Portland-limestone cement (CEM II/A-LL 42,5 R, Cementa, Sweden). The cement was stored in a closed glass jar during the duration of the study.

\section{B. Method}

Isothermal calorimetry is the measurement of heat production rate (thermal power) from small $(1-100 \mathrm{~mL})$ samples at constant temperature. This is a common technique in cement science and technology [5,27], but it is also used in, for example, pharmaceutical science and technology (then often under the name "microcalorimetry" [28]). Note that isothermal calorimetry is quite different from solution calorimetry or semiadiabatic calorimetry that are also used in the field of cement, but that are much less useful for the present type of study.

The present study was made at $25^{\circ} \mathrm{C}$ with an I-Cal Flex (Calmetrix, USA). This instrument has eight calorimeters in one thermostat, and the baseline stability in the present measurements was about $3 \mu \mathrm{W}$. The samples were in $20 \mathrm{~mL}$ polymer vials. The calorimeters were calibrated electrically and the baselines were taken using vials with water.

The measurements presented in this paper were made during a 140 day period using the same cement. As the used calorimeter can run eight samples simultaneously, a sample without any aggregates was run in each set of measurements. Figure 2(a) shows the results of all twelve such measurements. It is seen that the repeatability is good and that the cement did not change its hydration properties during the experimental period.

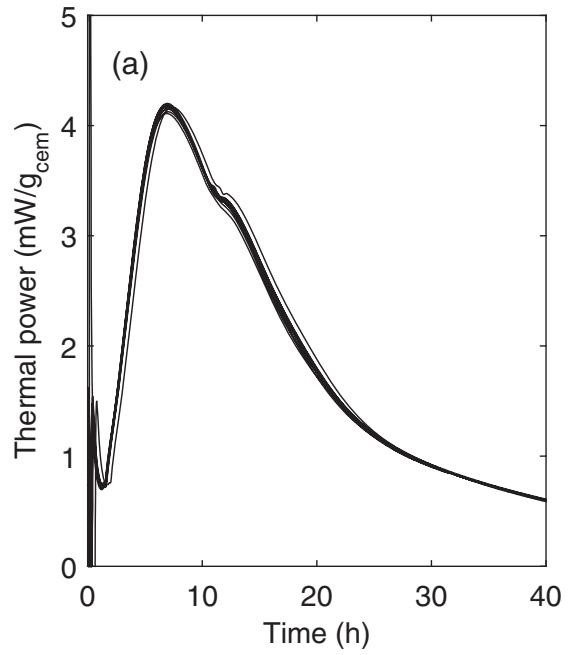

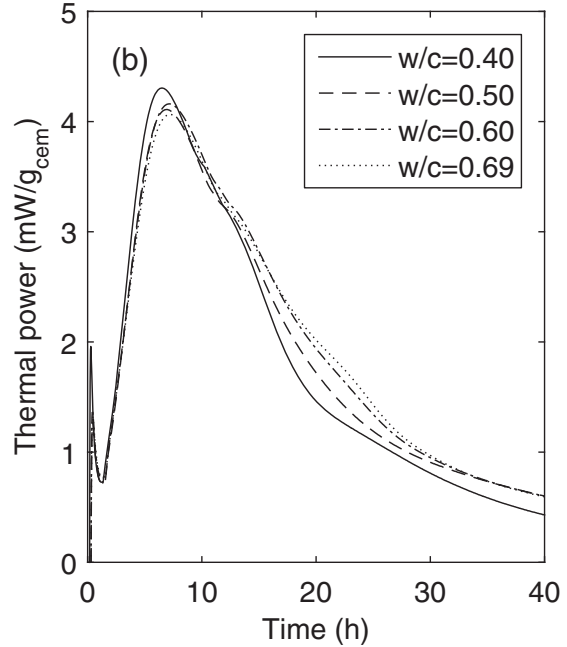

FIG. 2. Results of isothermal calorimetry on cement paste (no aggregate) discussed in the text. (a) Twelve repeats of hydration measurements made over a 140 day period. (b) Results for different water/cement ratios. 
For a cement paste the amount of water is expressed as the water/cement ratio and this ratio was 0.5 in the present measurements. However, it is possible that the amount of water available for the cement hydration was slightly lower in some cases as the added materials could take up water or contain small particles that hold water. As seen in Fig. 2(b), there is only a minor influence of the water/cement ratio on the hydration kinetics. A slightly earlier onset of the main reaction for low water/cement ratios [not possible to see in Fig. 2(b)] is because the ionic concentrations, needed to start the reaction, are reached more quickly when there is less water. The slowing down of the reaction rate for water/ cement ratio of 0.4 which is seen at around 15 hours is caused by a lack of available water.

The following measurement procedure was used: (i) Proper masses of the cement and the added material was weighed into all eight measurement vials in one measurement series. (ii) The vials with the dry components were shaken to mix the dry components. (iii) Water was added to one sample, which then was capped, mixed for $30 \mathrm{~s}$ on high speed on a test tube (vortex) mixer, and charged into calorimeter. (iv) Point (iii) was repeated until all samples were charged into the calorimeter. The time for starting all eight samples was about 10 min. The start time for each sample was when water was added to the dry material. In the present measurements the mass of cement and water was 4 and $2 \mathrm{~g}$, respectively (water/cement ratio 0.5 ). The test tube shaker was modified so that it had a holder for the vial. The rotating speed was $1400 \mathrm{rpm}$.

The measurements were made by successively adding higher and higher masses of the material interest to the $6 \mathrm{~g}$ cement paste. The water/cement ratio was thus constant, but the water/solids ratio decreased when higher amounts of the tested materials were added.

\section{RESULTS}

Representative results are given in Fig. 3 and summarized in Table II. It is seen that different types of behavior
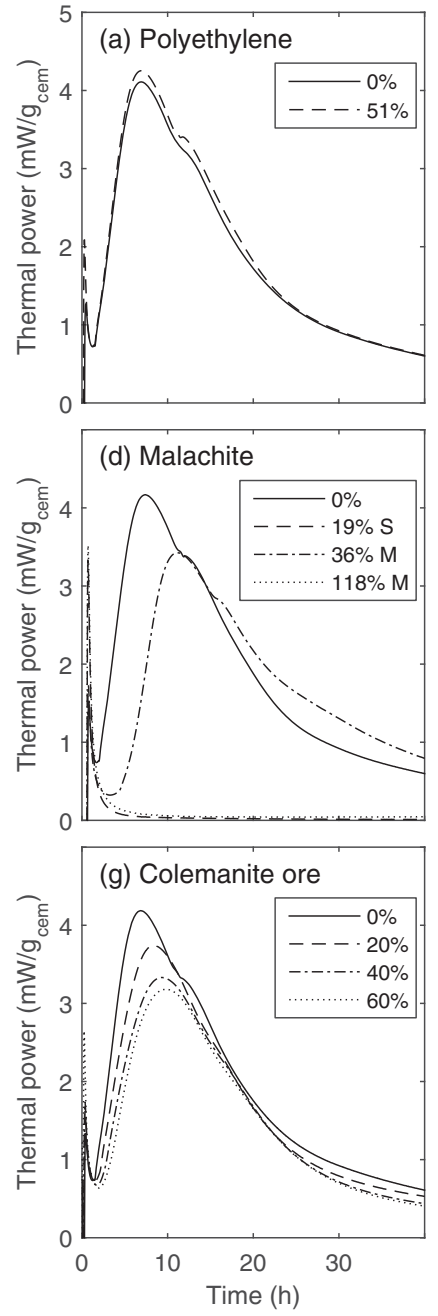
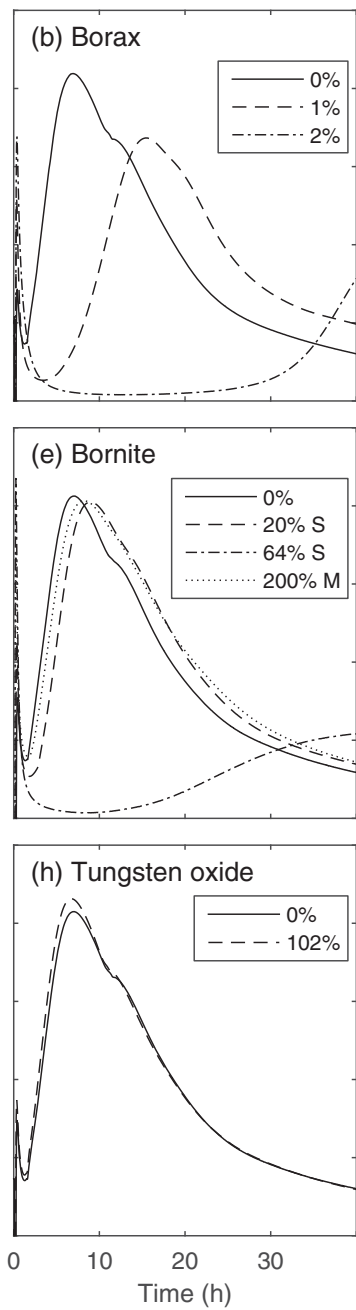
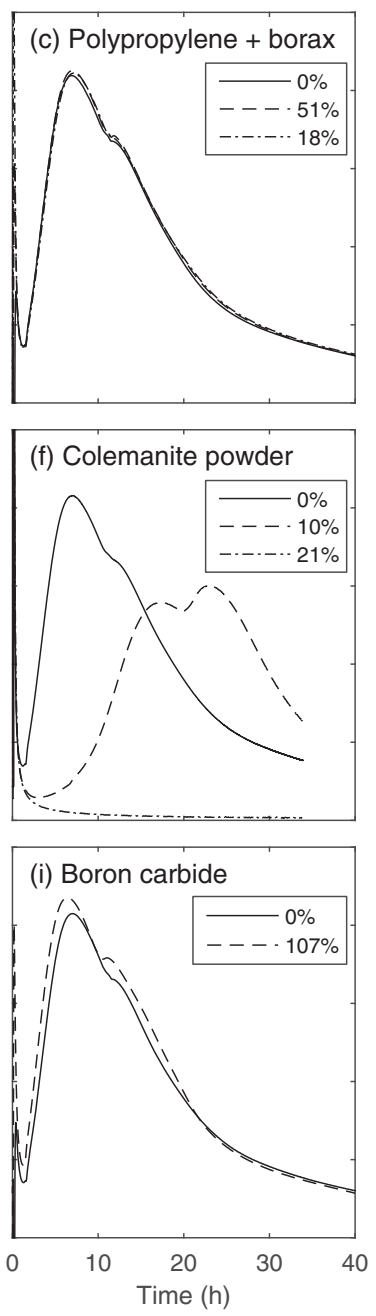

FIG. 3. Results from tests with isothermal calorimetry of compatibility between hydrating cement and different materials used for radiation shielding. The samples and the used concentrations are given in Table I and the results are described in Table II. 
TABLE II. The materials used and the result of the calorimetric measurements. The lettering corresponds to Fig. 1.

\begin{tabular}{|c|c|c|}
\hline A & Polyethylene (PE) & No influence from added material \\
\hline $\mathrm{B}$ & Borax & $\begin{array}{l}\text { Already } 1 \% \text { borax lowers the initial thermal powers and gives a significant retardation. } \\
\text { Higher concentrations severely modify the hydration kinetics. }\end{array}$ \\
\hline $\mathrm{C}$ & Polypropylene (PP) with borax & No influence of addition; borax must be encapsulated within the polymer. \\
\hline $\mathrm{D}$ & Malachite & $\begin{array}{l}\text { The malachite ore completely kills the hydration reaction, except for a small amount of } \\
\text { the medium (M) particles that only give a slight disturbance. }\end{array}$ \\
\hline $\mathrm{E}$ & Bornite & $\begin{array}{l}\text { Only a slight retardation except for } 64 \% \text { of the small (S) particles that severely } \\
\text { modifies the hydration kinetics. }\end{array}$ \\
\hline $\mathrm{F}$ & Colemanite powder (pure) & Pure colemanite powder strongly affects the hydration. \\
\hline G & Colemanite ore & Raw colemanite influences the hydration, but much less than the colemanite powder. \\
\hline $\mathrm{H}$ & Tungsten oxide & Inert; only a very slight increase in reaction rate at high replacement ratio; \\
\hline I & Boron carbide & Inert; only a very slight increase in reaction rate at high replacement ratio. \\
\hline
\end{tabular}

occur depending on which material is tested, the amount of material, and (in some cases) the particle sizes.

\section{DISCUSSION}

\section{A. General issues}

It is common to use isothermal calorimetry [29] to check the influence of chemical additives (for example superplasticizers and accelerators) or supplementary cementitious materials (SCMs) [30]; see for example references $[6,31,32]$. Typically paste samples with different concentrations of the additives or SCMs are then made. If the added component is only added in small amounts (like admixtures), fixed masses of water and cement are used, but if a component is added in a substantial amount and takes part in the hydration process (like SCMs), this approach cannot be used, and it is then logical to instead work with constant water/binder ratio (where the binder is cement $+\mathrm{SCM})$.

In the present case the added materials could potentially both have a chemical influence (like admixtures) and decrease the available water for the cement hydration by absorbing water, but they are not likely to react like SCMs. We therefore chose to keep the masses of water and cement constant, and to add the materials to be tested. The water/ cement ratio and the mass of hydrating cement paste $(6 \mathrm{~g})$ was thus the same in all measurements. As the materials to be tested were added to the $6 \mathrm{~g}$ cement paste, the heat capacity of the different samples was not the same. As we used the same reference heat capacity for all calorimeters (see Ref. [33] for a discussion of references in calorimetry), there could have been an issue with the thermal balance of the calorimeters. In isothermal heat conduction calorimeters the noise is lowest when the sample and reference has the same heat capacity. However, the noise was low in all the present measurements, so the thermal imbalance did not influence the result.

The above sample proportioning approach could lead to a lack of water when a high amount of added fine materials was used. This could have two consequences. First, it will influence the fluidity and possibility to mix the samples.
However, all samples mixed well in the test tube shaker even if the samples with higher amounts of material and with more fine material were less fluid. Second, with the used approach the effective water/cement ratio may decrease for the higher additions of fine material that will bind some water. However, this is not a problem as the hydration kinetics are quite insensitive to changes in water/ cement ratio [cf. Fig. 2(b)]. Lower water/cement ratios will only give a slightly earlier onset of the main hydration peak and a slightly higher maximum thermal power [34]. To this may be added a "filler effect," that small particles tend to increase the onset and rate of hydration [35] as they act as nucleation sites for the precipitation reactions during the initial part of the hydration.

Concrete is made of cement, water and aggregates (sand and rocks). For workability and strength it is important to optimize the size fractions of the aggregate so that the finer particles fill out the spaces between the larger ones. Materials with shielding properties will replace part of either the sand or the rocks (or both), depending on their particle size. If the shielding particles are inert (like most normal aggregate) the cement hydration will still proceed as normal, but if they contain substances that influence the hydration rate problems can occur. In many cases smaller particles with higher surface area will give more problems than larger particles as they will contain and release more contaminants. In the present study we have used small particles $(<6 \mathrm{~mm})$ and it is probable that large particles would have given less effect on the hydration.

\section{B. The results}

Polyethylene and polypropylene have excellent chemical stability under highly alkaline conditions. The polymers themselves should therefore be stable in a concrete pore solution and should not interfere with the hydration process, but processing aids and stabilizers added in the polymer manufacture could potentially interfere with hydration. However, no such interactions were seen for the used polymers [Fig. 3(a)] or for the polypropylene with 
borax [Fig. 3(c)]. Polypropylene without any borax was also tested (results not shown) and gave the same results as polyethylene. As borax has a dramatic influence on the hydration [Fig. 3(b)], the borax must be completely bound to or coated by the polypropylene in the polypropyleneborax composite. Borax $\left(\mathrm{Na}_{2}\left[\mathrm{~B}_{4} \mathrm{O}_{5}(\mathrm{OH})_{4}\right] \cdot 8 \mathrm{H}_{2} \mathrm{O}\right)$ is a known retarder of cement hydration [25] and other boron compounds are also known to have a retarding effect [26]. However, Kharita et al. [18] found that borax did not cause any significant effects on the strength of concrete, when added at concentrations up to $0.5 \%$ of the concrete mass. As this corresponds to an addition of about $5 \%$ of the cement mass, their results do not seem to agree with the present results (but it is not mentioned in Ref. [18] if the hydration was retarded).

The malachite gave a total collapse of the cement reaction, except at low concentration of the larger particles [Fig. 3(d)]. The bornite only gave problems with the high concentration of the smaller particles [Fig. 3(e)]. This indicates that the hydration disturbance of malachite and bornite is related to the surface of the particles, either through dissolution of the minerals or release of substances or particles from the surfaces. It is possibly the direct action of copper ions-both malachite and bornite are copper ores-that is responsible for the hydration disturbances. Soluble copper salts are retarders [8] and, except for lead and zinc, copper $\left(\mathrm{Cu}^{2+}\right)$ is the common cation that has the highest retarding action on Portland cement [2].

Two forms of the mineral colemanite were used: pure powder and larger particles of the ore. The pure powder retarded the hydration at $10 \%$, but killed the reaction and $21 \%$ [Fig. 3(f)], probably because of dissolution of boron, which - as is mentioned above-is a known retarder of cement hydration [26]. The ore only gave a slight lowering of the hydration peak [Fig. 3(g)], but as the thermal powers are lowered throughout the measurements when colemanite ore is present it seems that colemanite prevents some part of the cement hydration to take place.

The results for colemanite ore are qualitatively different from all other present results as the small second peak in the hydration curves disappears (cf. Fig. 4) when colemanite ore is added. This so-called "sulfate depletion peak" indicates that the pore solution is depleted of sulfate ions, and it is important for a proper (Portland) cement that this peak comes a few hours after the main peak [36]. In the manufacture of cement, soluble calcium sulfate (gypsum) is added to prevent the rapidly dissolving aluminate phase to form hydrates immediately on contact with water, as this gives flash set and severely retards the main strength giving reactions. In the presence of dissolved sulfate, the aluminates form other substances instead, so that the main reaction can proceed undisturbed. Cements sometimes have too little (or too slowly dissolvable) sulfate or the sulfate is immobilized or consumed by for example

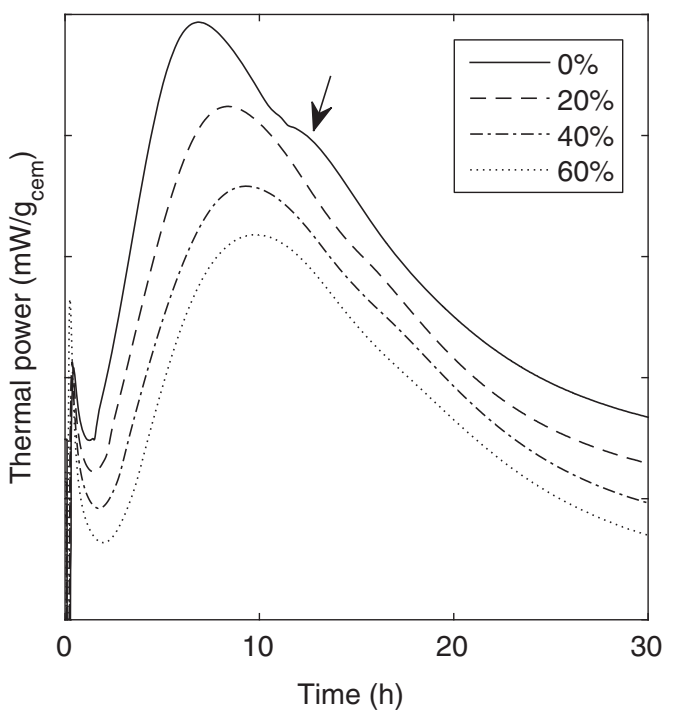

FIG. 4. The same result for cement paste with colemanite ore as in Fig. 3(g), but the hydration curves have been shifted in the y-direction to emphasize that the sulfate depletion peak at the arrow changes when the colemanite ore is added.

admixtures. In such cases the sulfate depletion peak tends to move to the left and sometimes even show up on the left side of the main peak. Such cements are not robust and, for example, a change in temperature or an increased dosage of an admixture may cause the hydration to collapse (ASTM C1679 [6] describes a calorimetric method to test if a system is undersulfated).

Two of the materials - tungsten oxide and boron carbide - could be added in equal masses to the cement without causing any significant changes in the hydration [Figs. 3(h) and 3(i)]. These materials can thus be considered to be inert with respect to the cement reaction. It is well known that small particles (fillers) can increase the rate of hydration by acting as nucleation sites for the cement reactions [35]. Such a behavior was seen for tungsten oxide [Fig. 3(h)] and boron carbide [Fig. 3(i)], which both contained fractions of fine particles.

For some of the tested materials the cement hydration showed a total collapse (or at least a sever retardation) above some concentration: borax [Fig. 3(b)], malachite [Fig. 3(d)] and colemanite powder [Fig. 3(f)]. The mechanisms behind this is not known.

\section{Shielding}

If concrete is to be supplemented by a certain element to shield, e.g., slow neutrons, it is the number of atoms of the element per volume that gives an effect. It is thus important to not only look at the mass of added material, but also to take into account the atomic fraction of the element of interest. Generally, the molar concentration, $c_{A}\left(\mathrm{~mol} \mathrm{~m}^{-3}\right)$, in the concrete of atom $\mathrm{A}$ added to a concrete through the substance B can be written as 


$$
c_{A}=\frac{m_{B}}{m_{c}+m_{w}+m_{a}+m_{B}} \cdot \frac{\rho \cdot x_{A B}}{M_{B}} .
$$

Here, $m(\mathrm{~g})$ are the masses of cement, water, normal aggregates, and substance B used to make a batch (or a cubic meter) of concrete, $\rho\left(\mathrm{g} \mathrm{m}^{-3}\right)$ is the density of the concrete, $x_{\mathrm{AB}}\left(\mathrm{mol} \mathrm{mol}^{-1}\right)$ is the amount of $\mathrm{A}$ in one mole of $\mathrm{B}$, and $M_{B}\left(\mathrm{~g} \mathrm{~mol}^{-1}\right)$ is the molar mass of $\mathrm{B}$. The ratio $x_{\mathrm{AB}} / M_{B}$ is thus an important factor. If we take boron as an example, there are several possible sources of this element. For boron carbide, boric acid, borax, and colemanite, the factor $x_{\mathrm{AB}} / M_{B}$ is respectively $0.072,0.016,0.011$ and $0.015 \mathrm{~mol} \mathrm{~g}^{-1}$. The number of boron atoms in a concrete mix is thus not only dependent on the mass of boron compound added, but also on how much boron there is in the compound. To get the same numbers of boron atoms in the concrete one needs to use nearly 5 times by mass more colemanite than boron carbide.

\section{Practical aspects}

It is unusual for papers on the shielding properties of concretes to mention anything about the rate of hydration. It can be that in some cases the concrete took a long time to hydrate, but when it was tested for strength and attenuation the hydration had taken place. However, a significantly retarded hydration is in most cases a problem, both for precast concrete and for concrete cast on site. For precast concrete it lowers the productivity as de-molding cannot be done as rapidly as if the concrete was unretarded, leading to the need for more molds and more space to store cast molds. On a worksite, retardation delays form stripping, so the concrete casting will take a longer time in the construction process. However, there are some cases where retardation may not be a problem. One possible such case is when concrete shielding blocks are cast in individual molds that are to become integral parts of the blocks.

Isothermal calorimetry is a useful method to screen materials to be added to a concrete mix, for example for retardation. As such measurements are made on small amounts of material and started relatively quickly (eight such measurements are started in about $1 \mathrm{~h}$ ) it is a good method for initial testing and screening. However, it cannot replace concrete testing, as many factors (for example the effect of admixtures and the effect of large-scale mixing) cannot be reliably simulated in the small scale calorimetric measurements on paste or mortar, and properties such as workability and strength cannot be assessed from calorimetric measurements.

Finally, cost is of course also a factor to take into account when optimizing shielding concrete. It is much less expensive to use mined abundant natural materials or waste materials, than to use highly processed or synthetic materials. However, more expensive materials that have higher concentration of shielding elements and show less interference with the cement hydration may still be preferable as they can give adequate shielding with smaller structural dimensions.

As is seen in the present results, physically interesting concrete mixes can exhibit a large variation in chemistry. In the current project, we now focus our efforts on those concretes with similar curing properties to regular concrete, so that the curing time and the structural engineering properties of the final material are compatible with construction projects whilst also offering improved shielding properties.

\section{CONCLUSIONS}

Isothermal calorimetry is a useful method to assess hydration disturbances as a first step in selecting materials to be incorporated into concrete to improve the neutron shielding effect in, e.g., neutron spallation facilities. Many different aggregates have been suggested for this, but as full scale tests of aggregates are expensive and time consuming, it is important to have fast ways to evaluate the feasibility of new aggregates. We show that isothermal calorimetry is an easy method to test whether potentially useful aggregates will disturb the cement hydration reaction, and that physically interesting aggregates gave a large variation in the hydration rate.

[1] C. K. Park, Hydration and solidification of hazardous wastes containing heavy metals using modified cementitious materials, Cement and Concrete Research 30, 429 (2000).

[2] M. I. Ojovan and W. E. Lee, An introduction to nuclear waste immobilisation, in An Introduction to Nuclear Waste Immobilization (Elsevier, New York, 2005), pp. 179-200.

[3] I. I. Bashter, Calculation of radiation attenuation coefficients for shielding concretes, Ann. Nucl. Energy 24, 1389 (1997).

[4] J. W. Bullard, H. M. Jennings, R. A. Livingston, A. Nonat, G. W. Schere, J. S. Schweitzer, K. Scrivener, and J. J. Thomas, Mechanisms of cement hydration, Cement and Concrete Research 41, 1208 (2011).

[5] L. Wadsö, F. Winnefeld, K. Riding, and P. Sandberg, Calorimetry, in A Practical Guide to Microstructural Analysis of Cementitious Materials, edited by K. Scrivener, R. Snellings, and B. Lothenbach (Taylor \& Francis, London, 2015).

[6] ASTM, C1679-14 standard practice for measuring hydration kinetics of hydraulic cementitious mixtures using isothermal calorimetry, 2014.

[7] C. Weeks, R. J. Hand, and J. H. Sharp, Retardation of cement hydration caused by heavy metals present in ISF slag used as aggregate, Cement and concrete composites 30, 970 (2008).

[8] J. I. Bhatty, Role of Minor Elements in Cement Manufacture and Use (Portland Cement Association, Skokie, IL, 1995).

[9] S. Peggs et al., ESS Technical Design Report, ESS, Lund, Sweden, 2013. 
[10] E. Yilmaz, H. Baltas, E. Kiris, I. Ustabas, U. Cevik, and A. M. El-Khayatt, Gamma ray and neutron shielding properties of some concrete materials, Ann. Nucl. Energy 38, 2204 (2011).

[11] U. Kaur, J. K. Sharma, P. S. Singh, and T. Sing, Comparative studies of different concretes on the basis of some photon interaction parameters, Appl. Radiat. Isot. 70, 233 (2012).

[12] A. B. Azees, K. S. Mohammed, M. M. a. B. Abdulla, K. Hussin, A. V. Sandu, and R. A. Razak, The effect of various waste material's content on the attenuation level of anti-radiation shielding concrete, Materials 6, 4836 (2013).

[13] A.S. Ouda, Development of high-performance heavy density concrete using different aggregates for gammaray shielding, Prog. Nucl. Energy 79, 48 (2015).

[14] D. D. Julio, C. P. Cooper-Jensen, H. Perrey, K. Fissum, E. Rofors, J. Scherzinger, and P. M. Bentley, A polyethyleneB4C based concrete for enhanced neutron shielding at neutron research facilities, Nucl. Instrum. Methods Phys. Res., Sect. A 859, 41 (2017).

[15] T. Piotrowski, M. Mazgaj, A. Zak, and J. Skubalski, Importance of atomic composition and moisture content of cement based composites in neutron radiation shielding, Procedia Eng. 108, 616 (2015).

[16] I. Akkurt, H. Akyildirim, B. Mavi, S. Kilincarslan, and C. Basyigit, Gamma-ray shielding properties of concrete including barite at different energies, Prog. Nucl. Energy 52, 620 (2010).

[17] S. J. Stankovic, R. D. Ilic, K. Jankovic, D. Bojovic, and B. Loncar, Gamma radiation absorption characteristics of concrete with components of different type materials, Acta Phys. Pol. A 117, 812 (2010).

[18] M. H. Kharita, S. Yousef, and M. AlNassar, Review on the addition of boron compounds to radiation shielding concrete, Prog. Nucl. Energy 53, 207 (2011).

[19] R. Boncukcuoglua, O. Icellib, S. Erzeneogluc, and M. M. Kocakerimb, Comparison of radioactive transmission and mechanical properties of Portland cement and a modified cement with trommel sieve waste, Cement and Concrete Research 35, 1082 (2005).

[20] R. Boncukcuoglua, M. T. Yilmaz, M. M. Kocakerimb, and V. Tosunoglu, Utilization of trommel sieve waste as an additive in Portland cement production, Cement and Concrete Research 32, 35 (2002).

[21] D. Rezaei-Ochbelagh and S. Azimkhani, Investigation of gamma-ray shielding properties of concrete containing different percentages of lead, Appl. Radiat. Isot. 70, 2282 (2012).
[22] D. R. Ochbelagh, S. Azimkhani, and H. G. Mosavinejad, Effect of gamma and lead as an additive material on the resistance and strength of concrete, Nucl. Eng. Des. 241, 2359 (2011).

[23] E. A. Wady and M. A. Bourham, Comparative study of different concrete composition as gamma-ray shielding materials, Ann. Nucl. Energy 85, 306 (2015).

[24] ASTM, C637 Standard specification for aggregates for radiation-shielding concrete, 2014.

[25] J. Kratochvíl, T. Opravil, and P. Divišs, The Effect of Boron and its Compounds on Setting of Portland Cement, Adv. Mater. Res. 1000, 16 (2014).

[26] R. Boncukcuog, M. T. Yılmaz, M. M. Kocakerimb, and V. Tosunog, Utilization of borogypsum as set retarder in Portland cement production, Cement and Concrete Research 32, 471 (2002).

[27] L. Wadsö, Applications of an eight-channel isothermal conduction calorimeter for cement hydration studies, Cement Int. 3, 94 (2005).

[28] G. Buckton, Applications of isothermal microcalorimetry in the pharmaceutical sciences, Thermochim. Acta 248, 117 (1995).

[29] L. Wadsö, Unthermostated multichannel heat conduction calorimeter, Cement Concrete Aggregates 26, 1 (2004).

[30] J. M. Paris, J. G. Roessler, C. C. Ferraro, H. D. DeFord, and T. G. Townsend, A review of waste products utilized as supplements to Portland cement in concrete, J. Cleaner Prod. 121, 1 (2016).

[31] F. Zunino and M. Lopez, Decoupling the physical and chemical effects of supplementary cementitious materials on strength and permeability: A multi-level approach, Cement and concrete composites 65, 19 (2016).

[32] $\mathrm{S} . \mathrm{Ng}$ and $\mathrm{H}$. Justnes, Influence of plasticizers on the rheology and early heat of hydration of blended cements with high content of fly ash, Cement and concrete composites 65, 41 (2016).

[33] L. Wadsö, Operational issues in isothermal calorimetry, Cement and Concrete Research 40, 1129 (2010).

[34] H. Hu, Z. Ge, and K. Wang, Influence of cement fineness and water-to-cement ratio on mortar early-age heat of hydration and set times, Construction and building materials 50, 657 (2014).

[35] T. Oey, A. Kumar, J. W. Bullard, N. Neithalath, and G. Sant, The Filler Effect: The Influence of Filler Content and Surface Area on Cementitious Reaction Rates, J. Am. Ceram. Soc. 96, 1978 (2013).

[36] W. Lerch, The influence of gypsum on the hydration and properties of portland cement pastes, Am. Soc. Testing Mater 46, 1252 (1946). 